\title{
Combined cavitary anomalies of the optic disc with maculopathy
}

\author{
Hirawat Rajshri ำ , ${ }^{1}$ Pratyusha Ganne, ${ }^{2}$ Nagesha C Krishnappa ${ }^{3}$
}

${ }^{1}$ Vitreo-retina, Gomabai Nethralaya and Research Centre, Neemuch, India

${ }^{2}$ Ophthalmology, All India Institute of Medical Sciences, Guntur, India

${ }^{3} \mathrm{~B}$ W Lions Superspeciality Eye Hospital, Bangalore, India

\section{Correspondence to}

Dr Hirawat Rajshri;

drrajshreehirawat@gmail.com

Accepted 12 May 2021
Check for updates

(C) BMJ Publishing Group Limited 2021. No commercial re-use. See rights and permissions. Published by BMJ.

To cite: Rajshri H, Ganne P, Krishnappa NC. BMJ Case Rep 2021;14:e244008. doi:10.1136/bcr-2021244008

\section{DESCRIPTION}

Cavitary optic disc anomalies can cause maculopathy. The most common of these associated with maculopathy is the optic disc pit. Very rarely, maculopathy can accompany optic disc coloboma. We report a case of combined cavitary disc anomalies (coloboma and disc pit) with maculopathy.

A 22-year-old young woman presented with decreased vision in the left eye (LE) for 6 months. The right eye (RE) had poor vision since childhood. Best corrected visual acuity was 2/60 in the $\mathrm{RE}$ and 6/24 in the LE. Fundus examination of the RE showed a retinochoroidal coloboma (RCC) involving the disc and macula (figure 1A) and the LE showed a cavitary defect involving inferior half of the disc with adjoining macular thickening and retinal pigment epithelium changes (figure 1B). Optical coherence tomography (OCT) scans through the left macula showed retinal schisis with foveal detachment (figure 1C).

Closer observation of the left optic disc revealed a circular greyish focal dip on the temporal margin suggestive of a pit (figure 2A, arrow). OCT scans through the optic disc in this region showed a narrow slit-like tract extending from the schitic retina to the depths of the lamina cribrosa (figure 2B,C, arrows). Vertical line scan through the larger cavitary defect of the left optic disc showed a widened scleral canal, posteriorly displaced lamina cribrosa with dysplastic retina lining the wall (figure 2D, arrow) consistent with a colobomatous defect.

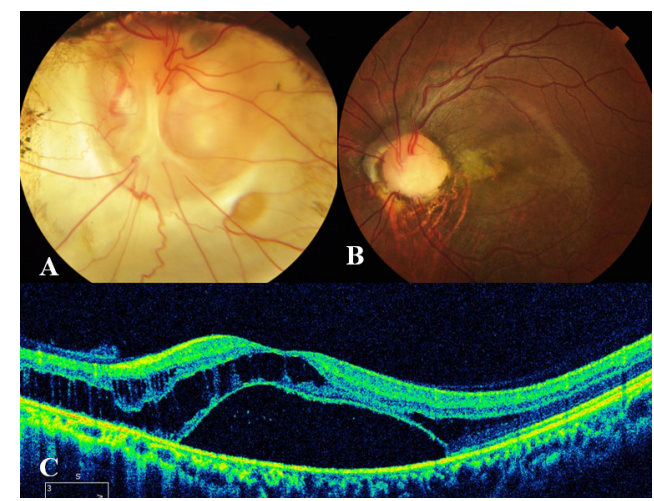

Figure 1 (A) Fundus photograph of the right eye showing a coloboma involving the disc and inferior retinochoroidal layer. (B) Left eye shows a cavitaryanamoly of the inferior half of the optic disc with adjoining retinal pigment epithelium changes and macular thickening. (C) Optical coherence tomography scan through the left macula showing retinal schisis in outer layers and subretinal fluid.

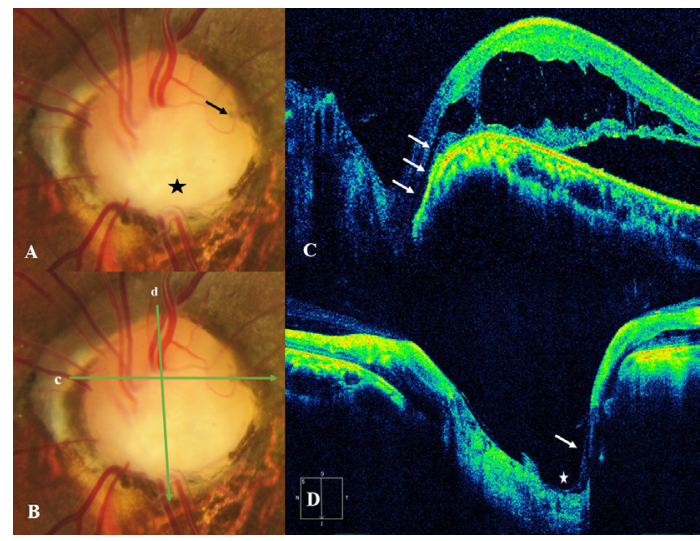

Figure 2 (A) Colour photograph of the left optic disc showing a sharply delineated, colobomatous excavation of the inferior half of the disc (asterisk) and a pit which is seen as a greyish focal depression on the temporal edge of disc (arrow). (B) The positions of the horizontal and vertical line scans corresponding to $(C)$ and $(D)$ are shown. (C) Horizontal line scan through the pit showing a narrow tract (arrows) extending deep into the lamina cribrosa. (D) Vertical scan though the disc showing an excavation in the inferior portion of the disc (asterisk) with herniation of the dysplastic retina (lacy appearance) (arrow).

Hence, a diagnosis of LE optic disc pit maculopathy with disc coloboma was made.

Optic disc pits are congenital cavitary anomalies of the disc which can present in isolation or in combination with an RCC. ${ }^{12}$ The coexistence of a disc coloboma with a pit is a rare entity. Maculopathy in such cases may develop either from disc pit or rarely from the coloboma. ${ }^{23}$ In a study on cavitary disc anomalies using swept source OCT, the author observed that the anatomical and physiological barrier between the subarachnoid space and the vitreous cavity is compromised by the presence of pits and colobomatous defects in the disc. In the present case, the presence of both these defects in close proximity could have increased the risk of developing maculopathy.

Optic disc colobomas need to be differentiated from acquired causes like glaucomatous cupping. A characteristic bowl-shaped white glistening defect with well-delineated edges in an abnormally large disc should raise suspicion of a disc coloboma. Dysplastic retina herniates into the excavation and takes on a lacy appearance on OCT. ${ }^{1}$ The macular thickening in cavitary disc anomalies presents with retinal schitic changes which may misdiagnosed as macular oedema of retinal vascular origin. Careful evaluation of the disc for pit lesions and 
demonstration of anatomical defects using OCT helps in arriving at the correct diagnosis. Vitrectomy with or without tamponade and laser have been shown to be successful in resolving maculopathy changes secondary to optic disc pits. ${ }^{4-6}$

This case emphasises the need for a meticulous imaging of the optic nerve head in cases with cavitary disc anomalies and maculopathy to arrive at the correct diagnosis and plan appropriate management.

\section{Learning points}

Cavitary disc anomalies can present with varied combinations including coloboma and pit.

- Meticulous imaging of the disc and macula is needed to demonstrate morphological changes and hence correct diagnosis.

- The management of such cases changes as many of the conditions are treatable.

Contributors RH evaluated the case. NCK prepared the manuscript and relevant literature search. PG reviewed the draft and finalized it.

Funding The authors have not declared a specific grant for this research from any funding agency in the public, commercial or not-for-profit sectors.
Disclaimer Case reports provide a valuable learning resource for the scientific community and can indicate areas of interest for future research. They should not be used in isolation to guide treatment choices or public health policy.

Competing interests None declared.

Patient consent for publication Obtained.

Provenance and peer review Not commissioned; externally peer reviewed.

\section{ORCID iD}

Hirawat Rajshri http://orcid.org/0000-0001-6493-5698

\section{REFERENCES}

1 Ohno-Matsui K, Hirakata A, Inoue M, et al. Evaluation of congenital optic disc pits and optic disc colobomas by swept-source optical coherence tomography. Invest Ophthalmol Vis Sci 2013:54:7769-78.

2 Kalogeropoulos D, Ch'ng SW, Lee R. Optic disc pit maculopathy: a review. Asia Pac J Ophthalmol 2019:8:247-55.

3 Hotta K, Hirakata A, Hida T. Retinoschisis associated with disc coloboma. Br J Ophthalmol 1999:83:123b.

4 Abe RY, Iguma Cl, Wen LC. A hybrid coloboma and optic disc pit associated with macular retinoschisis. BMC Ophthalmol 2019;19:212

5 Hirakata A, Okada AA, Hida T. Long-Term results of vitrectomy without laser treatment for macular detachment associated with an optic disc pit. Ophthalmology 2005; 112:1430-5

6 Shukla D, Kalliath J, Tandon M, et al. Vitrectomy for optic disk pit with macular schisis and outer retinal dehiscence. Retina 2012;32:1337-42.

Copyright 2021 BMJ Publishing Group. All rights reserved. For permission to reuse any of this content visit

https://www.bmj.com/company/products-services/rights-and-licensing/permissions/

BMJ Case Report Fellows may re-use this article for personal use and teaching without any further permission.

Become a Fellow of BMJ Case Reports today and you can:

- Submit as many cases as you like

Enjoy fast sympathetic peer review and rapid publication of accepted articles

- Access all the published articles

Re-use any of the published material for personal use and teaching without further permission

Customer Service

If you have any further queries about your subscription, please contact our customer services team on +44 (0) 2071111105 or via email at support@bmj.com.

Visit casereports.bmj.com for more articles like this and to become a Fellow 